\title{
Dissociative experiences, response bias, and fantasy proneness in college students
}

Citation for published version (APA):

Merckelbach, H. L. G. J., Muris, P. E. H. M., Horselenberg, R., \& Stougie, S. (2000). Dissociative experiences, response bias, and fantasy proneness in college students. Personality and Individual Differences, 28(1), 49-58. https://doi.org/10.1016/S0191-8869(99)00079-3

Document status and date:

Published: 01/01/2000

DOI:

10.1016/S0191-8869(99)00079-3

Document Version:

Publisher's PDF, also known as Version of record

\section{Please check the document version of this publication:}

- A submitted manuscript is the version of the article upon submission and before peer-review. There can be important differences between the submitted version and the official published version of record.

People interested in the research are advised to contact the author for the final version of the publication, or visit the DOI to the publisher's website.

- The final author version and the galley proof are versions of the publication after peer review.

- The final published version features the final layout of the paper including the volume, issue and page numbers.

Link to publication

\footnotetext{
General rights rights.

- You may freely distribute the URL identifying the publication in the public portal. please follow below link for the End User Agreement:

www.umlib.nl/taverne-license

Take down policy

If you believe that this document breaches copyright please contact us at:

repository@maastrichtuniversity.nl

providing details and we will investigate your claim.
}

Copyright and moral rights for the publications made accessible in the public portal are retained by the authors and/or other copyright owners and it is a condition of accessing publications that users recognise and abide by the legal requirements associated with these

- Users may download and print one copy of any publication from the public portal for the purpose of private study or research.

- You may not further distribute the material or use it for any profit-making activity or commercial gain

If the publication is distributed under the terms of Article $25 \mathrm{fa}$ of the Dutch Copyright Act, indicated by the "Taverne" license above, 


\title{
Dissociative experiences, response bias, and fantasy proneness in college students
}

\author{
Harald Merckelbach*, Peter Muris, Robert Horselenberg, Suzanne Stougie \\ Department of Psychology, Maastricht University, PO Box 616, 6200 MD, Maastricht, The Netherlands
}

Received 12 October 1998; received in revised form 29 January 1999; accepted 5 March 1999

\begin{abstract}
In two studies, the connection between dissociative experiences as measured by the Dissociative Experiences Scale (DES) and memory distortions was examined. In the first study, DES scores of female students $(N=42)$ were not found to be related to reality monitoring failures. There was, however, a significant association between DES and false positive memory failures, suggesting a response bias in participants scoring high on the DES. In the second study, students $(N=70)$ completed the DES, a measure of fantasy proneness, and the Life Events Inventory (LEI). The LEI lists a large number of discrete events and requires respondents to indicate whether these events have happened to them before the age of 10. A positive connection between DES and LEI was found, such that higher DES scores were accompanied by more positive answers to the LEI. The connection between DES and positive response tendencies to LEI items was evident for both neutral and negative items and was carried by fantasy proneness. Taken together, the data indicate that high DES scores are related to a positive response bias tendency. This may have substantial implications for retrospective studies that attempt to link high DES scores to traumatic antecedents. (C) 1999 Elsevier Science Ltd. All rights reserved.
\end{abstract}

Keywords: Dissociative experiences; DES; Fantasy proneness; Memory

\section{Introduction}

Over the past few years, several studies have addressed the frequency of dissociative experiences (e.g., derealization, depersonalization, amnesia) in normal and clinical populations

\footnotetext{
* Corresponding author. Tel.: +31-32-3881945; Fax: + 31-43-3615735.

E-mail address: H.Merckelbach@Psychology.Unimass.nl (H. Merckelbach)

0191-8869/99/\$ - see front matter (C) 1999 Elsevier Science Ltd. All rights reserved.

PII: S0191-8869(99)00079-3
} 
(see, for a review, van IJzendoorn \& Schuengel, 1996). The large majority of these studies has relied on the Dissociative Experiences Scale (DES; Bernstein \& Putnam, 1986), a 28-item selfreport questionnaire that measures the frequency of various types of dissociative experiences. The DES is not only a widely used research instrument, but it is also recommended as a screening tool for dissociative disorders that are thought to have a traumatic etiology (e.g., dissociative identity disorder, dissociative amnesia; Ross, 1997). Meanwhile, some authors have expressed concerns about the suitability of the DES as a screening tool for dissociative psychopathology (Frankel, 1990, 1996; Hacking, 1995; Merckelbach, Muris \& Rassin, 1999). The bottom line of their critique is that dissociation is an ill-defined concept that is difficult to separate from relatively benign phenomena such as everyday cognitive failures and fantasy proneness. Indeed, previous studies have found robust correlations between the DES and measures of cognitive failures and/or fantasy proneness (e.g., Merckelbach et al., 1999; Rauschenberg \& Lynn, 1995).

The potential implications of findings such as these are twofold. To begin with, due to its close links to benign characteristics, it might well be the case that the DES produces a high frequency of false positive cases when it is used as a screening tool for dissociative psychopathology. Germane to this issue is a study by Sandberg and Lynn (1992, p. 722) who noted that "the 8 subjects who scored in the upper $2 \%$ of the population on the DES failed to meet DSM-III criteria for a dissociative disorder, which suggests that the DES, when used with nonclinical samples, is likely to yield a large number of false positives for dissociative disorders". A second implication has to do with retrospective research on the causal connections between dissociation and trauma. If it is accepted that high dissociators also score high on measures of fantasy proneness and memory failures then the question arises how reliably their retrospective accounts of childhood events are (e.g., Rauschenberg \& Lynn, 1995). While it is true that high DES individuals more often report aversive childhood events than do control individuals, there is also research showing that the DES does not correlate with independent data on traumatic experiences (e.g., hospital records; Sanders \& Giolas, 1991). In the words of van IJzendoorn and Schuengel (1996, p. 376): "The link between traumatic experiences and dissociation is not based on convincing data that is independent of the respondents' autobiographical memory".

The present studies addressed the question whether high DES individuals display memory biases that might contribute to erroneous reports of autobiographical events. In this context, two types of memory biases are relevant. To begin with, the content of various DES items (e.g., "Some people find that they cannot remember whether they have done something or just have thought about doing that thing; for example, not knowing whether they have just mailed a letter or have just thought about mailing it") suggests that the DES might be sensitive to reality monitoring disruptions (Johnson, Hashtroudi \& Lindsay, 1993). Reality monitoring refers to the capacity to discriminate between memories of events that really happened and memories of events that were only imagined. Reality monitoring failures may give rise to powerful illusory memories (e.g., Parks, 1997). A possible link between dissociative tendencies and reality monitoring failures is also suggested by the robust correlation between DES and measures of individual proneness to everyday lapses and minor blunders (e.g., the Cognitive Failures Questionnaire; CFQ; see Merckelbach et al., 1999).

A second type of memory bias that might be connected to dissociative tendencies is 
confabulation. It is important to stress that we use the term confabulation in a rather broad way to refer to memory failures that also include relatively benign errors such as endorsing logically plausible, but false positive items (e.g., Roediger, Wheeler \& Rajaram, 1993). A possible connection between dissociation and false positive response confabulations is suggested by the correlation between DES and fantasy proneness (e.g., Merckelbach et al., 1999).

The present studies sought to explore the links between DES, reality monitoring disruptions, and false positive confabulations in non-clinical samples. The relevance of this type of study is obvious: if it could be shown that high dissociators exhibit reality monitoring disruptions and/ or confabulations, then caution is warranted in interpreting their self-reports of aversive childhood events.

\section{Study 1}

\subsection{Method}

\subsubsection{Participants}

The sample consisted of 42 female undergraduate students who volunteered to participate in the experiment. Their mean age was 20 years $(S D=1.2$; range: $19-24$ years). Subjects were tested in a large group session. They were told that the experiment was about selecting adequate themes for advertisement campaigns.

\subsubsection{Slide presentation}

Subjects underwent a reality monitoring task that was modeled after the task described by Intraub and Hoffman (1992). More specifically, they were shown a series of 40 slides. Half of the slides were straightforward photographs of common objects or situations (e.g., a horse, an umbrella, a building) taken from the International Affective Picture System (Lang, Ohman \& Vaitl, 1988). The other half of the slides consisted of short paragraphs describing a scene or object ("scissors on a desk"; "a church against a background of small houses"). Ten out of 20 paragraphs corresponded to pictures that were shown (e.g., "a brown horse"). The 20 paragraph and 20 photograph slides were presented in a random sequence. Each slide was presented for $5 \mathrm{sec}$. After slide offset, subjects rated on a 7-point scale how good they thought the theme (paragraph or photograph) was for advertisement purposes. Interslide intervals were $10 \mathrm{sec}$.

\subsubsection{Questionnaires}

Following the series of 40 slides, subjects completed the Dissociative Experiences Scale (DES; Bernstein \& Putnam, 1986), the Cognitive Failures Questionnaire (CFQ; Broadbent, Cooper, Fitzgerald \& Parkes, 1982), and the Creative Experiences Questionnaire (CEQ; Merckelbach, Muris, Schmidt, Rassin \& Horselenberg, 1998a). Completion of these questionnaires took about $15 \mathrm{~min}$.

The DES (Cronbach alpha $=0.88$ ) is a self-report instrument containing 28 items that address dissociative experiences such as disturbances in memory, awareness, and cognition. 
Subjects indicate on 100-mm visual analog scales the degree to which the experiences described by the items apply to them (anchors: $0=$ not at all; 100=very much). Scores are averaged across items to obtain a mean DES score. A large number of studies have found support for the psychometric qualities of the DES (van IJzendoorn \& Schuengel, 1996). That is, the DES possesses excellent internal consistency and test-retest stability (e.g., Bernstein \& Putnam, 1986). In addition, individuals with dissociative psychopathology display higher DES scores than control individuals (e.g., Putnam et al., 1996) and DES scores correlate significantly with self-reported traumatic events (e.g., Chu \& Dill, 1990; DiTomasso \& Routh, 1993; Nijman et al., 1999).

The CFQ (Cronbach alpha=0.91) is a 25-item self-report instrument that measures the frequency of everyday lapses and minor blunders (e.g., "Do you forget appointments?"). Subjects indicate on a 5-point scale how often they have experienced each cognitive failure in the past month (anchors: $0=$ never; $5=$ very often). Item scores are summed to obtain a total CFQ score. Merckelbach, Muris, Nijman, and de Jong (1996) summarize evidence to show that the psychometric properties of the Dutch CFQ are satisfactory.

The CEQ (Cronbach alpha $=0.80$ ) is a 25 -item measure of fantasy proneness that is scaled in the true/false form. CEQ items were derived from the extensive case descriptions of fantasy proneness provided by Wilson and Barber (1983). Typical examples are "In general, I spend at least half of the day fantasizing or daydreaming" and "My fantasies are so vivid that they are like a good movie". The number of yes-answers is summed to yield a total CEQ score. There is solid evidence for the reliability and validity of the CEQ (Merckelbach et al., 1998a).

\subsubsection{Memory test}

After subjects had completed the DES, CFQ, and CEQ, they were given a surprise recognition-test. This test contained 40 items of which 10 pertained to photographs that subjects had seen, 10 pertained to paragraphs that subjects had read, 10 referred to stimuli of which subjects had seen both photographs and paragraphs, and 10 referred to new objects or situations that were not included in the slide series. Subjects were instructed to indicate whether or not they had seen the item during the slide series and if so, whether they had seen it as a paragraph, a photograph or as both paragraph and photograph. Thus, subjects could make two types of memory failures: misidentifying a paragraph as a photograph or vice versa (i.e., reality monitoring errors; maximum score $=20$ ) and false positive responses, that is, cases

Table 1

Pearson correlations between dissociation (DES), fantasy proneness (CEQ), cognitive failures (CFQ), reality monitoring $(\mathrm{RM})$ errors, and confabulation $(N=42)$

\begin{tabular}{lllr}
\hline & DES & CEQ & CFQ \\
\hline CEQ & $0.55^{\mathrm{c}}$ & & \\
CFQ & $0.33^{\mathrm{b}}$ & 0.15 & \\
RM errors & 0.09 & 0.09 & 0.07 \\
Confabulation & $0.39^{\mathrm{b}}$ & $0.25^{\mathrm{a}}$ & -0.14 \\
\hline
\end{tabular}

${ }^{\mathrm{a}} p<0.10 ;{ }^{\mathrm{b}} p<0.05 ;{ }^{\mathrm{c}} p<0.01$ (one-tailed). 
in which subjects reported a picture and/or a paragraph when, in fact, neither a picture nor a paragraph had been presented during the slide series (confabulations; maximum score $=10$ ).

\subsection{Results and discussion}

Mean scores on the DES, CFQ, and CEQ were $23.6(S D=12.1), 43.3(S D=10.4)$, and 7.9 $(S D=3.8)$, respectively. Mean reality monitoring errors and confabulations were 0.95 $(S D=1.36$; maximum $=5)$ and $0.50(S D=1.02$; maximum $=4)$, respectively. Table 1 shows the Pearson product-moment correlations between questionnaire scores and recognition errors. As can be seen, the association between DES and reality monitoring errors failed to reach significance. However, the correlation between DES and confabulation (i.e., false positive recognition errors) did attain significance. While there were no robust connections between CFQ and CEQ, on the one hand, and memory measures, on the other hand, the association between fantasy proneness (CEQ) and confabulation approached significance $(r=0.25$, $p=0.06$; one-tailed). Both CFQ and CEQ were significantly correlated with DES. Although partialling out the contribution of fantasy proneness (CEQ) attenuated the correlation between DES and confabulation, this correlation remained significant $(r=0.31, p<0.05)$.

\subsection{Discussion}

Three conclusions can be drawn from these results. To begin with, the correlations between DES, on the one hand, and CFQ and CEQ, on the other hand, were positive and significant, a finding that replicates the results of previous studies (e.g., Merckelbach et al., 1999; Rauschenberg \& Lynn, 1995). Apparently, critics of the DES (e.g., Frankel, 1990; 1996; Hacking, 1995; Spanos, 1996) are correct in assuming that this instrument is sensitive to relatively benign characteristics such as everyday cognitive failures and fantasy proneness. Secondly, the hypothesis that these characteristics would promote a relatively deficient reality monitoring in high dissociators was not borne out by the data. As a matter of fact, no connection was found between DES and reality monitoring. Interestingly, in what seems to be the only other study that explored the relationship between dissociation and reality monitoring, van den Hout, Merckelbach, and Pool (1996) also failed to find evidence for high dissociators exhibiting poor reality monitoring. That study relied on reality monitoring tasks tapping memory for actions (what did I do?). The authors argued that it may well be the case that high dissociators are characterized by a disturbed reality monitoring of perceptions (what did I see?) rather than actions and they suggested that their null findings might be explained along these lines. Clearly, the current study does not support such an interpretation. In the present study, perceptual reality monitoring was measured in the way proposed by Intraub and Hoffman (1992), but even so reality monitoring performance and dissociation were found to be unrelated. Yet, one potential limitation that qualifies this finding is that reality monitoring error scores tended to be quite low and this may have introduced a range restriction that attenuated correlations. Lastly, and most important, evidence was found to suggest that dissociation and false positive recognition tendencies (i.e., confabulation) co-vary. This connection was only partially mediated by fantasy proneness, because partialling out the 
contribution of fantasy proneness reduced the correlation between dissociation and confabulation, but did not make it disappear.

\section{Study 2}

The link between dissociation and confabulation found in Study 1 adds weight in favour of the view that certain memory biases may confound high dissociators' self-report of traumatic events (e.g., Spanos, 1996; Frankel, 1990). However, one could raise the question whether false positive response tendencies on a memory task that involves material without personal relevance have any implications for self-reports of autobiographical events. In other words, do positive response tendencies also occur when high dissociators are asked whether or not they have experienced certain types of life events? Germane to this issue is a study of Johnson, Edman and Danko (1995) who had subjects complete the DES as well as a 22-item "bad things" scale. A significant correlation between DES and scores on the bad things scale $(r=0.40)$ was found, such that high dissociators reported a higher frequency of negative life experiences. This correlation remained at the same level when items referring to severe trauma (e.g., sexual abuse) were removed from the bad things scale leaving only items in the scale that pertained to mildly aversive experiences (e.g., "I have been sold defective products"). While this finding is consistent with the idea of high dissociators overreporting aversive life experiences, there is an alternative explanation, namely that "persons reporting abuse are more sensitive to and/or better able to recall other negative events than those not reporting such abuse" (Johnson et al., 1995; p. 795). To circumvent these ambiguities, Study 2 took the following approach: undergraduates filled in a Life Events Inventory (LEI; e.g., Garry, Manning, Loftus \& Sherman, 1996) that covered a broad range of discrete life events, some of which were relatively neutral or even positive while others fell in the "bad things" category. If a false positive response tendency rather than a heightened sensitivity and/or better recall of aversive life experiences is characteristic for high dissociators, one would expect positive and significant correlations between DES and scores on both negative and neutral LEI items. Study 2 tested this prediction.

\subsection{Method}

A sample of 70 undergraduates (58 women) completed the DES (Cronbach alpha $=0.95$ ), CEQ (Cronbach alpha $=0.74$ ), and LEI (Cronbach alpha $=0.83$ ). Their mean age was 18.4 years $(S D=3.3$ years; range: $16-43$ years). Subjects volunteered to participate in a laboratory experiment that had nothing to do with the present study. During the preexperimental waiting period, they filled in several questionnaires among them the DES, CEQ, and LEI.

The LEI was developed for the purpose of this study, but closely followed the type of items described by Garry et al. (1996). It contains 60 items, each describing a highly specific and discrete event. Forty items pertain to neutral or even positive experiences (e.g., found a silver ring; went with my school to Disney land; collected small insects and put them in a glass jar), while 20 items refer to aversive events (e.g., almost drowned in the swimming pool; almost choked on a piece of candy). Subjects were asked to indicate on 7-point scales (anchors: 
$1=$ definitely did not happen; $7=$ definitely did happen ) how certain they were that the events listed by the items had happened to them before the age of 10 . Scores were averaged to obtain a total LEI score. In addition, scores were averaged for neutral and negative items of the LEI separately (LEI-Neutral and LEI-Negative, respectively).

\subsection{Results and discussion}

Mean scores on the DES, CEQ, and LEI were $20.1(S D=14.3), 7.9(S D=3.6)$, and 3.3 $(S D=0.58)$, respectively. Table 2 presents the Pearson product-moment correlations between DES, CEQ, DES controlling for CEQ, LEI-Total, LEI-Neutral, and LEI-Negative. As can be seen, there were positive correlations between DES and all three LEI measures (i.e., Total, Neutral, and Negative). Thus, the higher the DES score the stronger the tendency to indicate that LEI items had happened. This association was not restricted to negative LEI items, as the correlation between DES and LEI-Neutral also attained significance. In passing, it should be noted that the correlation between LEI-Negative and LEI-Neutral was positive and significant $(r=0.60, p<0.01)$.

The correlations between fantasy proneness (CEQ) and the various LEI indices were all positive and significant. As in Study 1 and in previous studies (Merckelbach et al., 1999; Rauschenberg \& Lynn, 1995), there was a robust association between DES and fantasy proneness. Partialling out the contribution of fantasy proneness, reduced the correlations between DES and the various LEI measures to practically zero (see right hand column Table 2).

A similar pattern of results was found when correlational analyses were restricted to women $(n=58)$. Again, there were positive correlations between DES and both LEI-Negative and LEI-Neutral $(r=0.50$ and $r=0.31$, respectively; $p$ 's $<0.01)$ that disappeared when the influence of fantasy proneness was partialled out. All in all, the present data suggest that high dissociators exhibit a positive response bias that is strongly linked to their heightened levels of fantasy proneness.

Table 2

Pearson (and partial) correlations between dissociation (DES), fantasy proneness (CEQ), and scores on the Life Events Inventory (LEI) $(N=70)$

\begin{tabular}{llll}
\hline & DES & CEQ & DES controlling for CEQ \\
\hline CEQ & $0.63^{\mathrm{a}}$ & & 0.04 \\
LEI Total & $0.39^{\mathrm{a}}$ & $0.53^{\mathrm{a}}$ & 0.00 \\
LEI Neutral & $0.29^{\mathrm{a}}$ & $0.41^{\mathrm{a}}$ & 0.08 \\
LEI Negative & $0.44^{\mathrm{a}}$ & $0.58^{\mathrm{a}}$ & \\
\hline
\end{tabular}

${ }^{\mathrm{a}} p<0.01$ (one-tailed). 


\section{General discussion}

Study 1 demonstrated that dissociative tendencies are accompanied by a false positive response style rather than a disrupted reality monitoring. Study 2 showed that dissociative tendencies are related to a heightened frequency of affirmative responses to items about highly diverse life events. This was true not only for negative items, but also for items referring to relatively neutral experiences. Unless one assumes that people with dissociative tendencies have a more eventful life than those without such tendencies, this finding indicates that high dissociators employ liberal criteria in deciding whether or not a given item corresponds to an autobiographical memory. The findings of Study 1 and 2 also suggest that these liberal criteria derive, at least in part, from fantasy proneness. A limitation of both studies is that they heavily relied on female college students. Thus, it remains to be seen whether these findings can be replicated in samples with a more balanced sex distribution and/or in clinical samples.

A number of authors have claimed that childhood abuse may act as a developmental antecendent of dissociative tendencies as measured by the DES (e.g., DiTomasso \& Routh, 1993; Chu \& Dill, 1990). For example, Chu and Dill (1990, p. 891) administered the DES as well as self-report measures of childhood trauma to a sample of psychiatric inpatients and concluded that "the correlation between some kinds of childhood abuse experiences and elevated Dissociative Experiences Scale scores strongly suggests that dissociative experiences are linked to childhood trauma. Certainly, childhood abuse and the presence of a posttraumatic or dissociative disorder should be suspected in patients who have substantial levels of dissociation". The results of the current studies make plain that this conclusion is problematic, because it ignores the possibility that trauma reports of high dissociators are compromised by a positive response bias. Further evidence for the presence of such a bias in high dissociators comes from three sources. To begin with, a number of studies (e.g., Merckelbach, Muris, Wessel \& van Koppen, 1998b; Ost, Fellows \& Bull, 1997) have explored the connection between DES and the tendency to accept misleading information as indexed by the Gudjonsson Suggestibility Scale (GSS; Gudjonsson, 1992, 1997). In general, these studies have found definite links between DES and suggestibility, such that higher DES scores are accompanied by higher suggestibility scores for misleading statements, even when these misleading statements pertain to autobiographical events (Ost et al., 1997). Secondly, in their laboratory study on the creation of pseudomemories, Hyman and Billings (1998) noted that high DES scores are a powerful predictor of the creation and acceptance of pseudomemories. Finally, several correlational studies have documented that compared to control subjects, subjects scoring high on the DES not only report more aversive childhood events, but also report more paranormal experiences (e.g., Ross \& Joshi, 1992; Wolfradt, 1997). Some authors have concluded from this that "paranormal experiences are dissociative in nature and linked to childhood trauma and other dissociative symptom clusters" (Ross \& Joshi, 1992, p. 360), but a more parsimonious explanation would be that due to a lowered response criterion, high DES individuals are more likely to report traumatic and paranormal experiences.

To sum up, then, the present findings indicate that high dissociators have a positive response bias mediated by fantasy proneness that may potentially compromise their autobiographical reports. Thus, caution is warranted in interpreting the correlation between DES and selfreported childhood trauma that has been noted in many studies (e.g., Chu \& Dill, 1990). This 
is not to say that aversive childhood experiences play no role in dissociative experiences. It may well be the case that such experiences underlie high DES scores, fantasy proneness and a positive response bias (e.g., Lawrence, Edwards, Barraclough, Church \& Hetherington, 1995). However, studies that rely on self-report measures of traumatic events are not suitable to evaluate this possibility.

\section{References}

Bernstein, E. M., \& Putnam, F. W. (1986). Development, reliability, and validity of a dissociation scale. Journal of Nervous and Mental Disease, 174, 727-735.

Broadbent, D. E., Cooper, P. F., Fitzgerald, P., \& Parkes, L. R. (1982). The cognitive failures questionnaire (CFQ) and its correlates. British Journal of Clinical Psychology, 21, 1-16.

Chu, J. A., \& Dill, D. L. (1990). Dissociative symptoms in relation to childhood physical and sexual abuse. American Journal of Psychiatry, 147, 887-892.

DiTomasso, M. J., \& Routh, D. K. (1993). Recall of abuse in childhood and three measures of dissociation. Child Abuse \& Neglect, 17, 477-485.

Frankel, F. H. (1990). Hypnotizability and dissociation. American Journal of Psychiatry, 147, 823-829.

Frankel, F. H. (1996). Dissociation: The clinical realities. American Journal of Psychiatry (Festschrift Supplement), 153, 64-70.

Garry, M., Manning, C. G., Loftus, E. F., \& Sherman, S. J. (1996). Imagination inflation: imagining a childhood event inflates confidence that it occurred. Psychonomic Bulletin \& Review, 3, 208-214.

Gudjonsson, G. H. (1992). The psychology of interrogations, confessions, and testimony. Chichester: Wiley.

Gudjonsson, G. H. (1997). Gudjonsson suggestibility scales. Hove: Psychology Press.

Hacking, I. (1995). Rewriting the soul: Multiple personality and the sciences of memory. Princeton, NJ: Princeton University Press.

Hyman, I. E., \& Billings, F. J. (1998). Individual differences and the creation of false memories. Memory, 6, 1-20.

Intraub, H., \& Hoffman, J. E. (1992). Reading and visual memory: Remembering scenes that were never seen. American Journal of Psychology, 105, 101-114.

Johnson, M. K., Hashtroudi, S., \& Lindsay, D. S. (1993). Source monitoring. Psychological Bulletin, 114, 3-28.

Johnson, R. C., Edman, J. L., \& Danko, G. P. (1995). Self reported negative experiences and dissociation. Personality and Individual Differences, 18, 793-795.

Lang, P. J., Ohman A., \& Vaitl, D. (1988). The international affective picture system. Gainesville, FL, Center for Research in Psychophysiology, University of Florida, Gainesville.

Lawrence, T., Edwards, C., Barraclough, N., Church, S., \& Hetherington, F. (1995). Modelling childhood causes of paranormal belief and experience: Childhood trauma and childhood fantasy. Personality and Individual Differences, 19, 209-215.

Merckelbach, H., Muris, P., Nijman, H., \& de Jong, P. J. (1996). Self-reported cognitive failures and neurotic symptomatology. Personality and Individual Differences, 20, 715-724.

Merckelbach, H., Muris, P., \& Rassin, E. (1999). Fantasy proneness and cognitive failures as correlates of dissociative experiences. Personality and Individual Differences, 26, 961-967.

Merckelbach, H., Muris, P., Schmidt, H., Rassin, E., \& Horselenberg, R. (1998a). De Creatieve Ervaringen Vragenlijst als maat voor "fantasy proneness" [The Creative Experiences Questionnaire (CEQ) as a measure of fantasy proneness]. De Psycholoog, 33, 204-208.

Merckelbach, H., Muris, P., Wessel, I., \& van Koppen, P. J. (1998b). The Gudjonsson Suggestibility Scale (GSS): further data on its reliability, validity, and metacognition correlates. Social Behavior and Personality, 26, $203-210$.

Nijman, H., Dautzenberg, M., Merckelbach, H., Jung, P., Wessel, I., \& Campo, J. (1999). Self-mutilating behavior of psychiatric inpatients. European Psychiatry, 14, 4-10.

Ost, J., Fellows, B., \& Bull, R. (1997). Individual differences and the suggestibility of human memory. Contemporary Hypnosis, 14, 132-137. 
Parks, T. E. (1997). False memories of having said the unsaid: some new demonstrations. Applied Cognitive Psychology, 11, 485-494.

Putnam, F. W., Carlson, E. B., Ross, C. A., Anderson, G., Clark, P., Torem, M., Bowman, E. S., Coons, Ph, Chu, J. A., Dill, D. L., Loewenstein, R. J., \& Braun, B. G. (1996). Patterns of dissociation in clinical and nonclinical samples. Journal of Nervous and Mental Disease, 184, 673-679.

Rauschenberg, S. L., \& Lynn, S. J. (1995). Fantasy proneness, DSM-III-R axis I psychopathology, and dissociation. Journal of Abnormal Psychology, 104, 373-380.

Roediger, H. L., Wheeler, M. A., \& Rajaram, S. (1993). Remembering, knowing and reconstructing the past. In D. L. Medin, The psychology of learning and motivation: current trends in theory and research, (vol. 30, pp. 97-134). New York: Academic Press.

Ross, C. A. (1997). Dissociative identity disorder: diagnosis, clinical features, and treatment of multiple personality. New York: Wiley.

Ross, C. A., \& Joshi, S. (1992). Paranormal experiences in the general population. Journal of Nervous and Mental Disease, 180, 357-361.

Sandberg, D. A., \& Lynn, S. J. (1992). Dissociative experiences, psychopathology and adjustment, and child and adolescent maltreatment in female college students. Journal of Abnormal Psychology, 101, 717-723.

Sanders, B., \& Giolas, M. H. (1991). Dissociation and childhood trauma in psychologically disturbed adolescents. American Journal of Psychiatry, 148, 50-54.

Spanos, N. P. (1996). Multiple identities \& false memories: a sociocognitive perspective. Washington, DC: American Psychological Association.

van den Hout, M. A., Merckelbach, H., \& Pool, K. (1996). Dissociation, reality monitoring, trauma, and thought suppression. Behavioural and Cognitive Psychotherapy, 24, 97-108.

van IJzendoorn, M. H., \& Schuengel, C. (1996). The measurement of dissociation in normal and clinical populations: meta-analytic validation of the Dissociative Experiences Scale (DES). Clinical Psychology Review, 16, 365-382.

Wilson, S. C., \& Barber, T. X. (1983). Fantasy-prone personality: implications for understanding imagery, hypnosis, and parapsychological phenomena. In A. A. Sheikh, Imagery: current theory, research, and application (pp. 340 387). New York: Wiley.

Wolfradt, U. (1997). Dissociative experiences, trait anxiety, and paranormal beliefs. Personality and Individual Differences, 23, 15-19. 